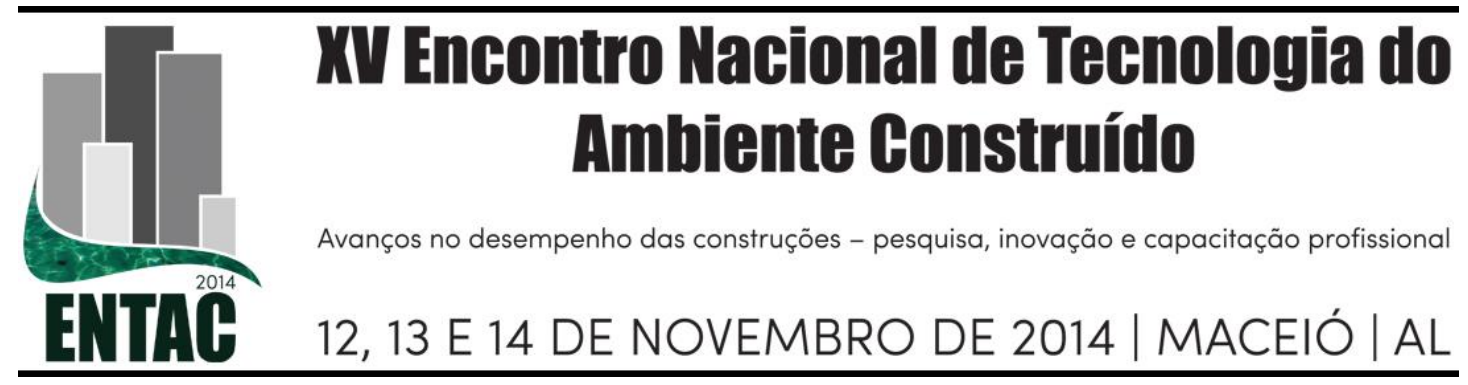

\title{
USO DA FERRAMENTA CONSTELAÇÃO DE ATRIBUTOS NO DIAGNÓSTICO DE DESEMPENHO DE ESPAÇOS ABERTOS
}

\author{
NIEMEYER, Carlos Augusto C (1); LABAKI, Lucila Chebel (2)
}

(1) PPG Fec-Unicamp: carlosniemeyer@hotmail.com (2) Fec-Unicamp: lucila@fec.unicamp.br

\begin{abstract}
RESUMO
Atualmente estudos de psicologia social e ambiental têm contribuído para a compreensão do urbano e das respostas sensoriais e emocionais do ser humano relativas ao ambiente em que vive. $\mathrm{O}$ artigo apresenta um estudo de caso afeto a avaliação ergonômica do ambiente construído adotando a ferramenta Constelação de Atributos em um espaço aberto. Introduz questões de psicologia ambiental e suas decorrentes relações de analise comportamentais geradas a partir dos aspectos configurados pela dinâmica de organização do ambiente construído. Para o desenvolvimento desse estudo foram realizadas entrevistas com 52 frequentadores da praça escolhidos aleatoriamente, procurando captar nas respostas níveis de empatia com o ambiente. Estabelecendo desse modo parâmetros de percepção cognitiva que possa servir de modelo auxiliar na avaliação de qualidade de desempenho de praças públicas. A metodologia pretende gerar modelos gráficos - constelação de atributos - que permitam identificar e qualificar atributos ligados a percepção do ambiente. $\mathrm{O}$ método prevê duas perguntas fundamentais acerca da percepção do espaço imaginário (subjetivo) e do espaço real (objetivo) com a compilação das respostas através do agrupamento de significados e afinidades geradas. Os resultados gerados permitem evidenciar graficamente os atributos que têm maior relevância com o ambiente estudado e, assim, a "distância psicológica" associada ao nível de percepção de conforto.
\end{abstract}

Palavras-chave: Avaliação Pós-ocupação, Constelação de Atributos, Psicologia Ambiental.

\begin{abstract}
Currently studies in social psychology and environment has contributed to the understanding of the urban and the answers sensory and emotional of the human being relating to the environment in which he lives. Has as the objective to present a study of a case affect the ergonomic assessments of the constructed environment adopting the tool "Constellation of Attributes" in the cognitive assessment in opened spaces. The approach introduces issues of environmental psychology and those arising from behavioral relations generated from the functional aspects configured by dynamic organization of the constructed environment. For the development of this study interviews with 52 frequenters of the square randomly chosen, trying to capture levels of empathy of the environment. Establishing this way parameters of cognitive perception that can serve as an auxiliary model in the assessment of the quality of environmental performance of public squares. The methodology intend to generate templates graphics the constellation of attributes - that allow visually and to qualify attributes associated with the perception of the environment by the user. The method previse two basic questions about the perception of the imaginary space (subjective) and the real space (objective) with compilation of answers through the grouping of meanings and affinities generated. The results generated allow evidencing attributes relevance with the studied environment and, consequently, the "psychological distance" associated with the perception of comfort.
\end{abstract}

Keywords: Evaluation Post-occupancy, Constellation of Attributes, Environmental Psychology. 


\section{INTRODUÇÃO}

Os equipamentos comunitários, em especial as praças públicas, objeto deste trabalho, vinculam-se a uma materialidade do ambiente construído permitindo consolidar a ideia de progresso civilizatório e de qualidade de vida estabelecendo aquilo que entendemos como função social da cidade e de ação politica sobre o espaço urbano.

Cabe à arquitetura, enquanto arte funcional, estabelecer a estrutura física em torno de nossas vidas ordenando e humanizando o habitat do homem. Por este aspecto a arquitetura é também encarada como uma "arte política" por cristalizar o domínio público e os valores sociais e culturais de longo prazo configurando um elemento mediador e simbólico da vida social (MAGALHÃES, 2001). Como tal, a arquitetura dá forma e estabelece valores e significações ao espaço urbano servindo de palco à urbanidade. LYNCH (1982:11) ilumina esse protagonismo da vida pública ao destacar que "os elementos móveis de uma cidade, especialmente as pessoas e as suas atividades, são tão importantes como as suas partes físicas e imóveis" e que sendo a cidade objeto de nossa percepção temos a necessidade de reconhecer o ambiente em que estamos.

Componentes funcionais do espaço citadino, as praças públicas são parte do sistema de espaços abertos da cidade, consistindo áreas de permanência e de convívio voltados a fruição dinâmica no interesse da promoção da sociabilidade no espaço urbano. Sua relevância para uma efetiva apropriação social vincula-se a qualidade ambiental e estética e um enfoque metodológico que preveja questões de coexistência cultural, conforto, pregnancia e sentido de pertencimento.

Atendendo a tais requisitos e quando devidamente mantido pelo poder público, a aceitação social de um espaço público é automática e reflete a construção de uma identidade morfológica configurando condições propícias a sua atratividade. Segundo MACEDO (1995), três fatores devem ser levados em consideração na permanência de um espaço aberto: sua adequação funcional, definida como sua correta conformação morfológica e dimensional permitindo uso apropriado a uma dada finalidade; sua adequação ambiental, afeto a questões de salubridade e desempenho aos diferentes climas; e sua adequação estética, função das diferentes expectativas sociais e padrões socioeconômicos. O conjunto estruturado desses componentes deve assim oferecer personalidade ao lugar, estar em harmonia com o meio, contribuir na imaginabilidade do ambiente urbano, ou seja, ser claro, perceptível, seguro e legível ao citadino (LYNCH, 1960; CULLEN, 1971).

As praças públicas, objeto deste estudo, são lugares tradicionais da morfologia urbana e assumem um protagonismo social, primeiro enquanto lugar de difusão da sociabilidade, e segundo ao incorporar a função lúdica, atividade regressiva e inspiradora na qual o individuo se envolve voluntariamente resultando em bem estar e desenvolvimento humano (DUMAZEDIER, 1973). Fundamental para o desenvolvimento psicossomático do individuo, não se concebe setores urbanos sem a existência de praças, cujo lazer oferecido pode assumir função ativa ou passiva em face das especificidades socioeconômicas e aspirações lúdicas da sociedade.

A despeito do esvaziamento da vida pública nos lugares abertos frente ao apelo midiático da cultura do consumo e da celeridade globalizada, com frequência cabe nos indagarmos que perspectiva haveria a praça pública nos tempos atuais? Destacamos que a praça resiste aos valores dominantes enquanto lugar do encontro na esfera pública assumindo funções especializadas a determinados segmentos e faixas etárias como o lazer ativo (jogos, esporte) e passivo ao ar livre (o descanso e a contemplação), o footing e, por fim, o lugar de ações culturais, funções essas que dificilmente a esfera 
privada poderia propiciar. Assim, o tema da praça pública é sempre atual, mas exige um constante repensar nas configurações morfológicas que atendam às características de lazer e sociabilidade nos contextos locais e temporais para a qual mantem forte seu poder de atratividade e usabilidade.

Sobre o ponto de vista de sua manutenção, a praça brasileira, apesar de existir em boa quantidade na maioria de nossas cidades, de um modo geral padece de uma conservação sistemática que recupere a agradabilidade nesses recintos ancestrais que se confundem com própria historia das cidades. Espoliadas e abandonadas, o que se observa são o retrato acabado da discricionariedade das politicas públicas impondo ao tecido urbano aquilo que TUAN (1980) chama de "topocídio" ou a eliminação do sentido cultural desses lugares, esvaziando as estruturas de efetivação desta apropriação numa espécie de obsolescência programada da vida pública.

O êxito ou desacerto no desenho ou redesenho de lugar público relaciona-se com a capacidade em articular dimensões e contextos sociais (históricos, econômicos, culturais) e arquitetônicos (tecnológicos, funcionais, legais, etc) sem perder de vista a dimensão humana que sempre o determina (MAGALHÃES, 2001). Fragilidades organizacionais tradicionalmente verificadas na condução de projetos como insuficiência de estudos prévios ou indefinição de objetivos e necessidades acabam por determinar muitas vezes uma "preponderância de aspectos técnicos e estéticos sobre aspectos funcionais e organizacionais", destaca MARTIN (2009:360), produzindo resultados insatisfatórios no seu desempenho físico ou cognitivo. Situação esta que pode ser contornada através de uma concepção projetual que valorize uma cultura de "construção progressiva e coletiva"; que maximize interações entre os diversos atores envolvidos no projeto (usuários, ente público, empreendedores, projetistas) e a percepção de que o projeto não se restringe a uma construção somente, mas a "um modo de funcionamento", um anseio de vivência relativa a um futuro (MARTIN, op. cit).

NUNES (2007) faz uma alusão crítica aos espaços concebidos na base da intuição individual do projetista, isento de aferições mais sensíveis da ambiência desejada pelo usuário, não raro resultando em equívocos que remetem a desorientações, desconforto e disfuncionalidade. Quando trabalhamos com espaços públicos o cliente é uma coletividade com aspirações comuns exigindo uma metodologia de intervenção que, numa linguagem e escala convenientes, capte anseios de uma concepção ideal que atenda as necessidades e características de usabilidade ali previstas. Desenvolver aquilo que TUAN (1980) chama de "sentimento de topofilia", fundado na apreciação estética, no favorecimento ao contexto urbano e aos estímulos sensoriais que, conjuntamente, potencializam condições favoráveis à construção de um ambiente agradável. TUAN (op. cit) ilumina a dicotomia "espaço" x "lugar" fundamental no entendimento do caráter afetivo do lugar, distinto, portanto, da materialidade fria do espaço físico e indiferenciado. Nessas condições, eleva-se o caráter de "pracialidade", expressão cunhada por QUEIROGA (2007), que podemos traduzir como um "estado de praça" apropriado pelo coletivo, permitindo acolhimento e congraçamento de nossas experiências, de nossos movimentos e de nossos anseios de apropriação do lugar.

O estudo de caso aqui apresentado pretende contribuir no entendimento prático dessas questões voltadas à concepção de espaços públicos mais eficientes no desempenho de suas funções sob um ponto de vista cognitivo. Propõem-se adotar aqui a ferramenta analítica denominada Constelação de Atributos, idealizada pioneiramente por Abraham Moles da Escola de Estrasburgo (1968), posteriormente desenvolvida por EKAMBISCHIMIDT (1974); método experimental já aplicado em análises de desempenho 
ergonômico do ambiente construído no interesse de apreender a chamada "consciência psicológica" do usuário e a percepção do espaço vivido (VILLAROUCO \& ANDRETO, 2008). Aplicada nas condições específicas de espaços abertos, o estudo em tela centra-se na qualidade vivencial voltada a atributos físicos e cognitivos ligada a sensações de segurança, conforto ambiental, mobiliário, funcionalidade, estética e manutenção, buscando uma lente investigativa nas condições existentes no sistema homem-ambiente.

\section{FUNDAMENTAÇÃO}

Cabe a ergonomia ambiental, disciplina que estuda as interações homem-ambiente oferecer os meios e técnicas necessárias para identificar e sistematizar ações de correção/prevenção de condições adversas que interferem no desempenho do ambiente construído e que se relaciona intrinsicamente com fatores fisiológicos, cognitivos, sociais, organizacionais e ambientais (MONT'ALVÃO \& VILLAROUCO, 2011; VASCONCELOS et ali, 2009 e 2010; VILLAROUCO \& ANDRETO, 2008). Questões relacionadas a conforto térmico, acústico e lumínico se colocam também presentes nas preocupações da interação homem-ambiente, configurando um contexto multidisciplinar que agrega os campos da arquitetura, da psicologia ambiental e da ergonomia.

Partindo do principio que as demandas psicossociais não são facilmente observáveis em face da subjetividade e intangibilidade a ponto de poder serem exteriorizadas e medidas (ELALI \& PINHEIRO, 2008; BONFIM, 2008), exige-se aplicação de metodologias investigativas oriundas da psicologia ambiental que permitam apreender esta dimensão oculta. Visando identificar e sistematizar os aspectos que interferem na usabilidade do lugar, bem como a forma mais adequada de percebê-los, os estudos de ergonomia ambiental contribuem para uma leitura mais rigorosa de desempenho do ambiente construído visando readequá-lo fisicamente às suas funções.

A abordagem foca essencialmente em um diagnóstico pós-ocupacional calcado em um processo informacional de análise cognitiva de um espaço aberto na perspectiva dada pela ergonomia ambiental, iluminando condições de adaptabilidade e conformidade do espaço comunal às atividades ali previstas. $O$ processo metodológico visa dar tangibilidade ao intangível, observa BONFIM (2008), permitindo dimensionar geometricamente emoções e sentimentos experienciados a partir de um processo analítico que visa estimular e captar elementos de percepção do usuário no ambiente. $O$ estudo visa oferecer um diagnóstico de usabilidade do recinto, questão sutil e fundamental ao projetista na condução de projetos pós-ocupacionais.

\section{MATERIAIS E MÉTODOS}

A pesquisa de campo foi realizada em fevereiro de 2014 no recinto da Praça Cândido Mota situada na área central da cidade de Caraguatatuba (SP). O total de respondentes foi estimado com base em critério estatístico considerando-se uma margem de erro de $5 \%$ e um grau de confiança de $95 \%$. Assim determinou-se o tamanho da amostra em 52 (cinquenta e dois) respondentes escolhidos aleatoriamente em diversas faixas etárias, com entrevistas aplicadas em horários diversos ao longo dos três turnos. A pesquisa seguiu as recomendações do protocolo do Comitê de Ética na Pesquisa (CEP), no que se refere ao caráter de pleno consentimento, privacidade e confidencialidade das informações obtidas em conformidade com os objetivos acadêmicos em tela. 
A metodologia adotada por diversos autores em análises ergonômicas do ambiente construído e que foca na percepção ambiental (VILLAROUCO \& ANDRETO, 2008; VASCONCELOS et ali, 2009; OLIVEIRA, 2013, entre outros) considera em seu diagnóstico a leitura de uma série de variáveis (atributos) levantadas e sistematizadas a partir das respostas obtidas afetas às duas realidades distintas aqui colocadas no contexto deste trabalho: a realidade vivida e a imaginabilidade do recinto. Perguntaschave de caráter investigativo endereçadas aos respondentes guiam este processo metodológico em duas etapas de procedimentos que dialogam-se analiticamente. A pergunta (1) remete ao campo do imaginário, aos desejos e anseios do usuário quanto a um espaço livre que, no seu ponto de vista, lhe causaria agradabilidade: Que imagens ou ideias lhe vêm a cabeça quando você pensa numa praça? O objetivo é determinar percepções positivas acerca de uma concepção ideal de praça enquanto ambiente de estar, pergunta esta em geral carregada de estereótipos pré-concebidos. A pergunta (2) remete a imagem da praça real: Que imagens ou ideias lhe vêm a cabeça quando você pensa nesta praça? Esta indagação capta a opinião particular sobre o recinto real já não influenciado por respostas ou comportamentos massificados ou estereotipados em geral transmitidos sutilmente na resposta anterior.

O modelo gráfico gerado a partir da tabulação realizada nos dados permite demonstrar visualmente a percepção do usuário sobre o recinto, onde a cadeia de atributos provocada permite destacar aquelas de maior relevância segundo sua "frequência" de aparição permitindo o cálculo das "distâncias psicológicas" (vide Quadros 1 e 2). Duas "constelações de atributos" (real e imaginaria) são assim geradas como resultado das codificações levantadas fornecendo um mapeamento das percepções objetivas e subjetivas atuantes que geram influência cognitiva na interface homem-ambiente.

As variáveis são representadas graficamente através da definição da probabilidade (Pi) de associação do atributo (i) com o objeto avaliado a partir da fórmula (a) e a "distância psicológica" (D) em cm que separa cada atributo do objeto de estudo com base na fórmula (b), descritas respectivamente (1):
(a) $P i=n i x \frac{100}{N}$
(b) $D=\frac{1}{\log P i}$

Onde, $\quad \mathrm{Pi}=$ probabilidade de associação do atributo $\mathrm{i}$

$\mathrm{D}=$ distância psicológica do atributo $(\mathrm{cm})$

$\mathrm{n}_{\mathrm{i}}=$ número de aparições do atributo $\mathrm{i}$

$\mathrm{N}=$ total de respostas

\section{RESULTADOS}

Na sequência geram-se Quadros demonstrativos (1 e 2) com os atributos quantificados e categorizados com as respectivas distâncias psicológicas calculadas com base na fórmula descrita concebidas com base na frequência do atributo. A partir dos valores das distancias psicológicas se procede a construção das respectivas Constelações que representam a materialização do fenômeno estudado (BONFIM, 2008). Aloca de forma gráfica a interação de fatores psicossociais, sociofísicos e histórico-culturais que atuam no nosso inconsciente resultando uma abordagem visual da percepção sensorial.

As configurações gráficas apresentadas se destacam pelo comprimento das barras definindo as "distâncias psicológicas" com suas respectivas classificações indicadas nos círculos. As categorias são representadas pelo código cromático associado ao Quadro com as medidas das barras (em centímetros) calculadas em função das frequências de aparecimento do atributo. A imagem dinâmica mostra o maior ou menor valor 
simbólico dado a cada atributo pelo usuário, assim distâncias maiores demonstram pouca afinidade enquanto as menores revelam maior afinidade a este ou aquele atributo. O desenho resultante dá tangibilidade ao fenômeno observado e exibe o nível de adaptação psicológica do usuário frente àquele espaço. A constelação de atributos fornece uma leitura da percepção simbólica do ambiente por um coletivo, portanto um diagnóstico de usabilidade do recinto permitindo associarmos analiticamente atributos imaginários e reais captando os anseios e graus de afetividade ali gerados.

Segue os quadros demonstrativos e suas respectivas construções gráficas finalizando a abordagem metodológica descrita:

\section{Quadro 1 - atributos associados a praça imaginária.}

\begin{tabular}{|c|c|c|c|c|}
\hline \multicolumn{5}{|c|}{$\begin{array}{c}\text { TABELA DE ATRIBUTOS ASSOCIADOS A PRAÇA IMAGINÁRIA } \\
\text { LOCAL DE PESQUISA: Praça Cândido Mota }\end{array}$} \\
\hline CATEGORIA & $\begin{array}{l}\text { ATRIBUTOS ASSOCIADOS AO } \\
\text { AMBIENTE }\end{array}$ & RESP & CLASSI & $\begin{array}{l}\text { DIST } \\
\text { PSI }\end{array}$ \\
\hline \multirow{5}{*}{$\begin{array}{l}\text { Conforto } \\
\text { ambiental }\end{array}$} & Muita árvore/sombra & 28 & 2 & 1,01 \\
\hline & Aconchegante/fresca & 11 & 10 & 1,68 \\
\hline & Plantas e flores & 4 & 15 & 6,33 \\
\hline & Presença de água/fonte & 4 & 15 & 6,33 \\
\hline & Som ambiente & 3 & 16 & 30,21 \\
\hline \multicolumn{2}{|r|}{ SUBTOTAL } & $\mathbf{5 0}$ & & \\
\hline Ergonomia & Bancos confortáveis & 39 & 1 & 0,87 \\
\hline \multicolumn{2}{|r|}{ SUBTOTAL } & 39 & & \\
\hline \multirow[t]{3}{*}{ Segurança } & Piso drenante & 6 & 13 & 2,99 \\
\hline & Pavimentação plana/acessível & 15 & 6 & 1,37 \\
\hline & Boa iluminação & 13 & 8 & 1,49 \\
\hline \multicolumn{2}{|r|}{ SUBTOTAL } & 34 & & \\
\hline \multirow[t]{9}{*}{ Funcionalidade } & Playground & 19 & 4 & 1,19 \\
\hline & Palco para apresentações & 9 & 11 & 1,96 \\
\hline & Banheiros limpos & 16 & 5 & 1,32 \\
\hline & Estares reservados/sombreados & 5 & 14 & 3,92 \\
\hline & Espaços amplos & 8 & 12 & 2,18 \\
\hline & Lixeiras & 14 & 7 & 1,42 \\
\hline & Bebedouro & 12 & 9 & 1,58 \\
\hline & Aparelhos para exercícios & 3 & 16 & 30,21 \\
\hline & Mesas com tabuleiros & 6 & 13 & 2,99 \\
\hline \multicolumn{2}{|r|}{ SUBTOTAL } & 92 & & \\
\hline \multirow{3}{*}{ Estética } & Jardins/paisagismo & 21 & 3 & 1,39 \\
\hline & Chafariz & 16 & 5 & 1,32 \\
\hline & Layout agradável & 12 & 9 & 1,58 \\
\hline \multicolumn{2}{|r|}{ SUBTOTAL } & 49 & & \\
\hline \multirow[t]{2}{*}{ Manutenção } & Manutenção de jardim & 5 & 14 & 3,92 \\
\hline & Limpeza geral permanente & 9 & 11 & 1,96 \\
\hline \multicolumn{2}{|r|}{ SUBTOTAL } & 14 & & \\
\hline \multicolumn{2}{|c|}{ TOTAL DE RESPOSTAS } & 278 & & \\
\hline \multicolumn{2}{|c|}{ TOTAL DE RESPONDENTES } & 52 & & \\
\hline
\end{tabular}


Quadro 2 - atributos associados a praça real.

\begin{tabular}{|c|c|c|c|c|}
\hline \multicolumn{5}{|c|}{$\begin{array}{c}\text { TABELA DE ATRIBUTOS ASSOCIADOS A PRAÇA REAL } \\
\text { LOCAL DE PESQUISA: Praça Cândido Mota }\end{array}$} \\
\hline CATEGORIA & $\begin{array}{l}\text { ATRIBUTOS ASSOCIADOS AO } \\
\text { AMBIENTE }\end{array}$ & RESP & CLASS & $\begin{array}{l}\text { DIST } \\
\text { PSI }\end{array}$ \\
\hline \multirow{3}{*}{$\begin{array}{l}\text { Conforto } \\
\text { ambiental }\end{array}$} & Boa sombra & 20 & 2 & 0,86 \\
\hline & Aconchegante/fresca & 8 & 9 & 2,18 \\
\hline & Insolada a tarde & 3 & 13 & 30,21 \\
\hline \multicolumn{2}{|r|}{ SUBTOTAL } & 31 & & \\
\hline \multirow{2}{*}{ Ergonomia } & Bancos desconfortáveis & 32 & 1 & 0,94 \\
\hline & Praça confortável & 4 & 12 & 6,33 \\
\hline \multicolumn{2}{|r|}{ SUBTOTAL } & 36 & & \\
\hline \multirow[t]{4}{*}{ Segurança } & Piso ruim/inseguro & 19 & 3 & 1,19 \\
\hline & Fechar rua interna & 7 & 10 & 2,49 \\
\hline & Ambiente inseguro & 7 & 10 & 2,49 \\
\hline & Escura a noite & 11 & 7 & 1,68 \\
\hline \multicolumn{2}{|r|}{ SUBTOTAL } & 44 & & \\
\hline \multirow[t]{8}{*}{ Funcionalidade } & Precariedade da feira de artesanato & 7 & 10 & 2,49 \\
\hline & Ausência de banheiro & 11 & 7 & 1,68 \\
\hline & Layout pouco funcional da praça & 7 & 10 & 2,49 \\
\hline & Ausência de playground & 3 & 13 & 30,21 \\
\hline & Ausência de bebedouro & 9 & 8 & 1,96 \\
\hline & Ausência de atrativos & 3 & 13 & 30,21 \\
\hline & Ausência de lixeiras & 20 & 2 & 0,86 \\
\hline & Desvalorizada & 5 & 11 & 3,92 \\
\hline \multicolumn{2}{|r|}{ SUBTOTAL } & 65 & & \\
\hline \multirow[t]{5}{*}{ Estética } & Revitalizar o paisagismo & 19 & 3 & 1,19 \\
\hline & Melhorar as podas & 13 & 6 & 1,49 \\
\hline & Falta cor & 8 & 9 & 2,18 \\
\hline & Ligar fonte & 9 & 8 & 1,96 \\
\hline & Praça feia & 9 & 8 & 1,96 \\
\hline \multicolumn{2}{|r|}{ SUBTOTAL } & 58 & & \\
\hline \multirow[t]{3}{*}{ Manutenção } & Manutenção geral precária & 17 & 4 & 1,27 \\
\hline & Abandonada & 14 & 5 & 1,42 \\
\hline & Ambiente sujo/vandalizado & 13 & 6 & 1,49 \\
\hline \multicolumn{2}{|r|}{ SUBTOTAL } & 44 & & \\
\hline \multicolumn{2}{|c|}{ TOTAL DE RESPOSTAS } & 278 & & \\
\hline \multicolumn{2}{|c|}{ TOTAL DE RESPONDENTES } & 52 & & \\
\hline
\end{tabular}


Figura 1. Constelação de Atributos referente a praça imaginária

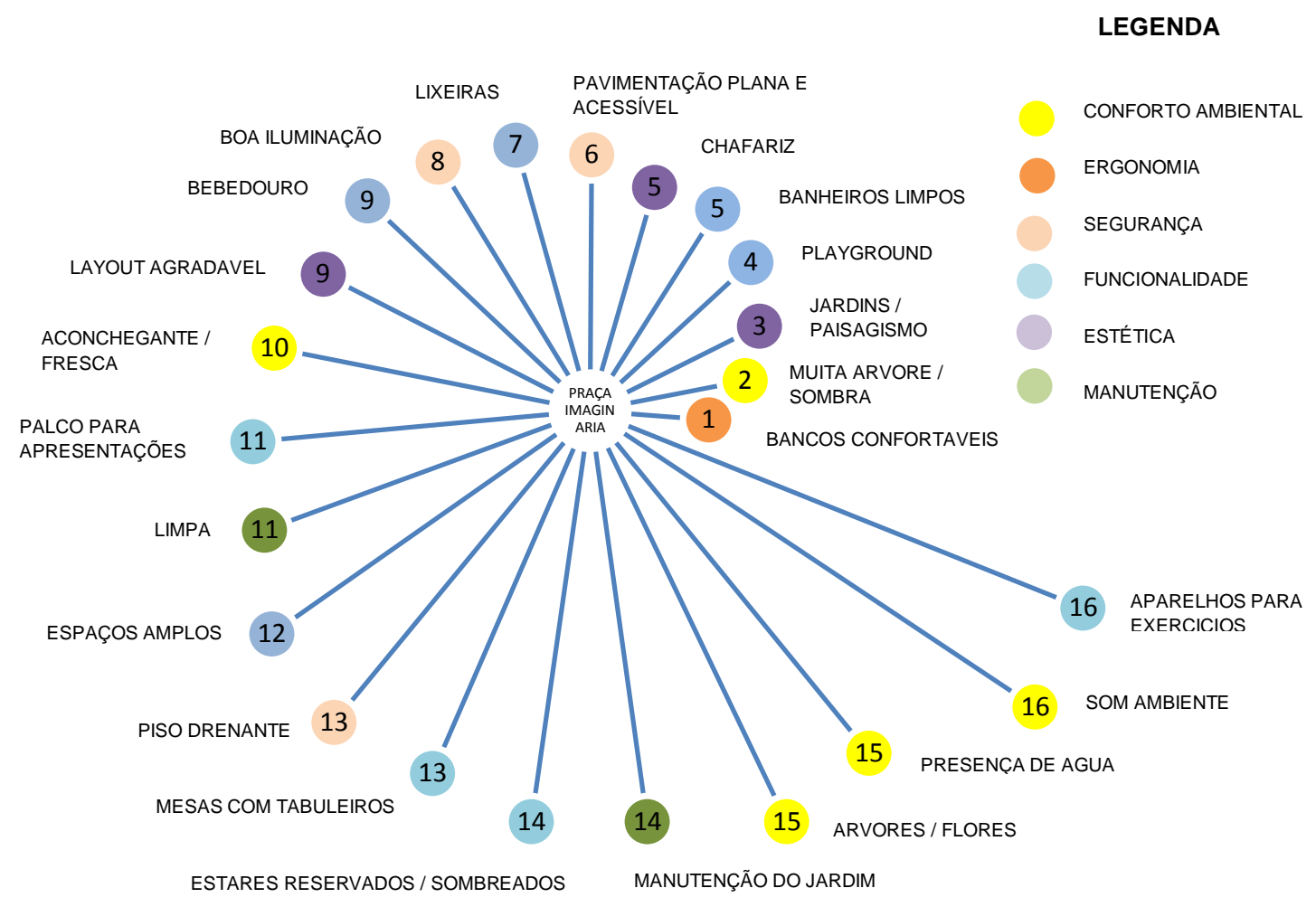

Figura 2. Constelação de Atributos referente a praça real

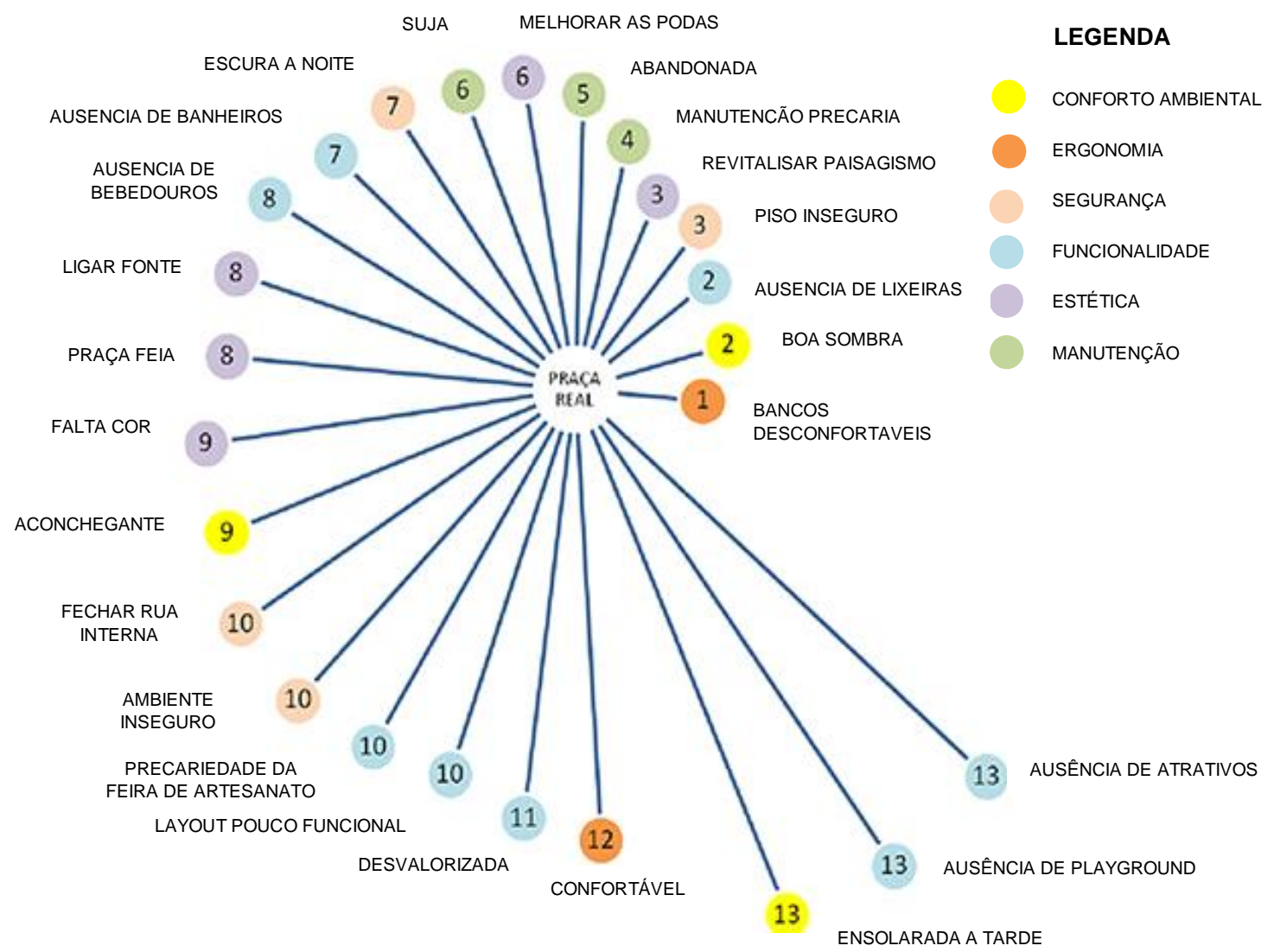




\section{Figura 3. Imagem renderizada da Praça Cândido Mota em seu contexto urbano.}

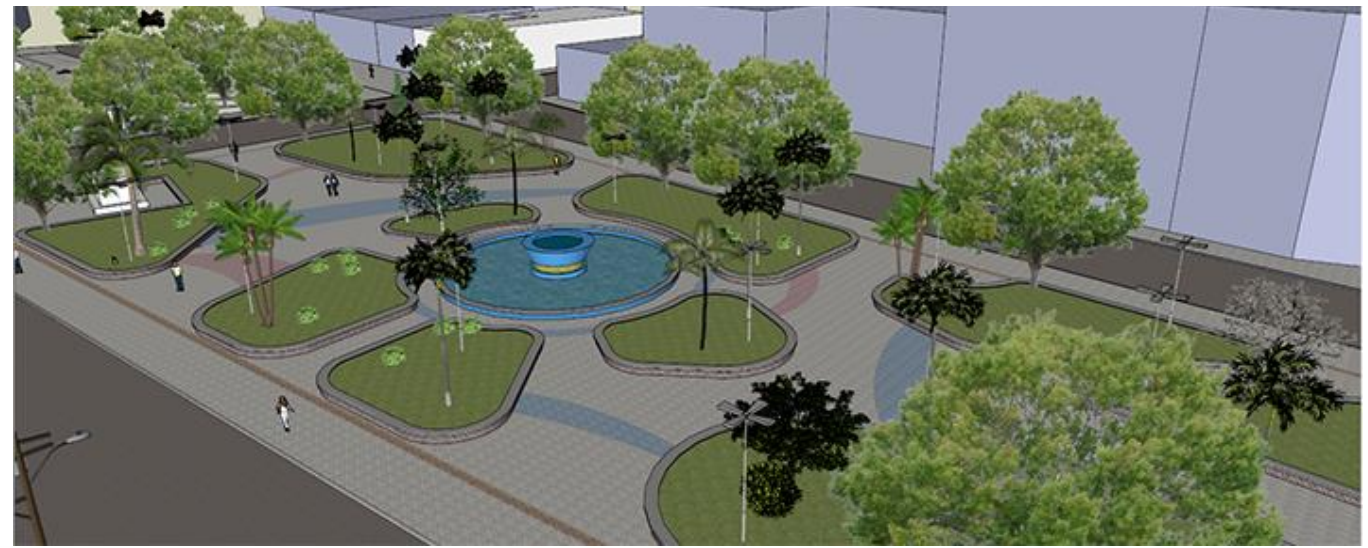

\section{CONCLUSÕES}

Os resultados mostram que a percepção da praça imaginária é fortemente marcada por expectativas ligadas a funcionalidade, estética e conforto ambiental. Não raro, durante as entrevistas, remeteu-se a concepções tradicionais embasando o anseio por lugares "acolhedores" do passado contrapondo ao ambiente real distante do imaginado. Constatou-se que qualidades funcionais e estéticas exercem importância na percepção da praça real, indicando insatisfação com um fato concreto e incômodo como, por exemplo, a ausência de banheiros públicos, bebedouros, lixeiras, fonte quebrada e outros que impactam na atratividade do lugar. Também se destaca na visível distância psicológica de atributos pontuais como desconforto ao sol da tarde, ausência de playground e de outros atrativos, uma escassa insatisfação social com esses atributos.

A estética do ambiente real recebeu significativas citações, em especial à necessidade de revitalização do paisagismo como melhoria nas podas e conserto da fonte luminosa, percepção esta mais forte entre idosos mais afetos ao fenômeno da lembrança. Na leitura da praça imaginária, a categoria estética empata em citações com a de conforto ambiental denunciando que o desempenho térmico angaria grande importância cognitiva tanto quanto a performance paisagística. Contudo, na praça real a estética assume uma ascendência sobre o conforto ambiental, o que pode ser explicado pelo fato de já conter expressiva presença do componente arbóreo, garantindo a priori qualidade térmica aos lugares resultando em prioridade a outros componentes funcionais.

Cabe observar que é justamente na ergonomia que encontramos o atributo de maior frequência tanto na imagem idealizada quanto no objeto real: mobiliário inadequado impacta diretamente na usabilidade do recinto, sobretudo para aqueles que utilizam a praça de forma sistemática. Atributos negativos ligados a ergonomia (bancos desconfortáveis), manutenção (em geral precária), segurança (pavimentação ruim) e ausência de paisagismo (estética) granjearam unanimidade na avaliação da praça real, o que constitui sinais evidentes de uma inadequação ambiental que impacta diretamente a qualidade da vivência nesses lugares.

De forma que o estudo permitiu aferir a eficácia da ferramenta Constelação de Atributos no diagnóstico ergonômico de praças públicas e no conhecimento do universo de valores e representações que os usuários fazem desses recintos. Colocado nesses termos, a Constelação de Atributos torna-se uma ferramenta eficiente na condução de diagnósticos pós-ocupacionais mais precisos ao vislumbrar aspectos psicológicos ocultos e, por isso, difíceis de lidar, permitindo, num processo de investigação 
criterioso, um olhar corretivo e determinante para valorização social e cognitiva do lugar público.

\section{REFERÊNCIAS}

BINS ELY, V. H. TURKIENICZ, B. Método da grade de atributos: avaliando a relação entre usuário e ambiente. Ambiente Construído, v. 5, n. 2, p. 77-88, 2005

BOMFIM, Zulmira Á Cruz, Afetividade e Ambiente Urbano: uma proposta metodológica pelos mapas afetivos. In: PINHEIRO \& GUNTHER, Hartmut (Org), Métodos de Pesquisa nos Estudos pessoa-ambiente. São Paulo: Casa do Psicólogo, 2008, p. 253-280.

CULLEN, Gordon, Paisagem Urbana. Lisboa: Ed. 70, 1986.

DUMAZEDIER, J, Lazer e cultura popular. São Paulo: Ed. Perspectiva, Debates, 1973.

EKAMBI-SCHMIDT, J. La percepción del hábitat. Barcelona: G. Gili, 1974.

FONSECA, Juliane F, RHEINGANTZ, Paulo A, O ambiente está adequado? Prosseguindo com a discussão. Produção, v.19, no. 3. São Paulo, Set/dez 2009, p 502-513.

ELALI, Gleice A \& PINHEIRO, José Q. Autobiografia ambiental: buscando afetos e cognições da experiência com ambientes. In: PINHEIRO \& GUNTHER, Hartmut (Org), Métodos de Pesquisa nos Estudos pessoa-ambiente. São Paulo: Casa do Psicólogo, 2008, p. 217-251.

FAZON, Pierre. Ergonomia, São Paulo: Ed. Edgard Blucher, 1ª Edição, 2009.

LYNCH, Kevin, A imagem da cidade. Lisboa: Ed. 70, 1982.

MARTIN, C, O ergonomista nos projetos arquitetônicos. In: FAZON, (2009), p. 357-369.

MACEDO, Silvio S, Quadro do Paisagismo no Brasil. São Paulo: FAU-USP, Guapá, 1999.

Silvio S, Espaços Livres. Apostila de curso. São Paulo: FAU-USP/It, 1995.

MAGALHÃES, Manuela R, A arquitectura Paisagista. Lisboa: Editorial Estampa, 2001.

MONT'ALVÃO, Claudia \& VILLAROUCO, Vilma (Org), Um novo olhar para o projeto: a ergonomia no ambiente construído. Teresópolis (RJ): 2AB, 2011.

NUNES, Claudia, O ergodesign no contexto do idoso. Revista Convergência, Lisboa, 2007.

OLIVEIRA, Gilberto Rangel, $O$ método avaliação e percepção de atribuições para projetos: uma contribuição à ergonomia do ambiente construído. Tese de Doutorado. PUC. Rio de Janeiro, 2013.

QUEIROGA, Eugênio Fernades, O lugar da Praça e a pracialidade nos lugares. Notícias ABAP, ano 4, no. 36. ABR/2003.

TUAN, Yi-fu. Topofilia - um estudo da percepção, atitudes e valores do meio ambiente. São Paulo: DIFEL, 1980.

VASCONCELOS, Christina S.F, et ali, Contribuição da Psicologia Ambiental na análise ergonômica do ambiente construído. Revista Ação Ergonômica. Rio de Janeiro: ABERGO/UFRJ, volume 5, no. 3, p.14-20, DEZ/2010.

Christina S.F. Avaliação Ergonômica do Ambiente Construído: estudo de caso em uma biblioteca universitária. Ação Ergonômica, no. 4, no. 1, Rio de Janeiro. ABERGO/UFRJ, volume 4, no. 1, p.5-25, OUT/2009.

VILLAROUCO, Vilma, ANDRETO, Luis F, Avaliando desempenho de espaços de trabalho sob o enfoque da ergonomia do ambiente construído. Produção, vol.18 no.3, São Paulo SET/DEZ 2008. 